\title{
PENINGKATAN KEPERCAYAAN DIRI DENGAN PUBLIC SPEAKING UNTUK PROGRAM BERITA BAGI PELAJAR SEKOLAH PKBM BAKTI ASIH CILEDUG TANGERANG
}

\author{
Ricky Widyananda Putra ${ }^{1 *}$, Jeanie Annissa ${ }^{2}$ \\ ${ }^{1}$ DKV Universitas Budi Luhur, Indonesia \\ ${ }^{2}$ IImu Komunikasi Universitas Budi Luhur, Indonesia \\ *rickywidyanandaputra@budiluhur.ac.id
}

\begin{abstract}
In real life, communication can be broadly divided into two main streams, namely verbal communication and nonverbal communication. Verbal communication can be broadly interpreted as communication that uses spoken language as the medium. While nonverbal communication is communication that makes nonverbal means as a medium of implementation. These things cannot be judged as something lacking or even more so because their need to behave in this way still dominates their whole life and behavior. Verbal communication, in this case related to speech, does not arise from a vacuum. He exists because there is a response to the situation that surrounds him. In addition to the things mentioned above, this speaking skill is very sustainable with Indonesian culture because Indonesian people tend to have a stronger verbal tradition than their writing tradition. It would be nice if their energy was directed to the mastery of public speaking. In the public speaking method, it allows students to be able to expose all their abilities in terms of speaking. But more than that, learners will learn how to cultivate self-confidence in themselves. They must be able to master their fear and shame in public. The subject of this community service is the community consisting of teenagers, fathers, mothers who are members of PKBM Bakti Asih, Ciledug-Tangerang, Banten, CiledugTangerang. The reason for choosing this institution is because PKBM Bakti Asih is a package $A, B$ and $C$ educational institution that is developing in Tangerang City, besides that the institution is universally open to scientific studies. It is hoped that with this community service activity, which contains some communication material and media understanding that relies on the public speaking method, so that it raises awareness that public speaking can increase self-confidence in an individual.
\end{abstract}

Keywords: communication; public speaking; confidence; news

\begin{abstract}
Abstrak
Dalam kehidupan nyata, komunikasi secara garis besar bisa terbagi menjadi dua arus besar yaitu komunikasi verbal dan komunikasi nonverbal. Komunikasi verbal secara luas bisa dimaknai sebagai komunikasi yang menggunakan bahasa lisan sebagai mediumnya. Sedangkan komunikasi nonverbal adalah komunikasi yang menjadikan sarana nonverbal sebagai media pelaksananya. Hal-hal tersebut, tidak bisa dinilai sebagai sesuatu kekurangan atau terlebih kelemahan karena mungkin kebutuhan mereka untuk berperilaku demikian masih mendominasi keseluruhan hidup dan tata perilakunya. komunikasi verbal, dalam hal ini berhubungan dengan pidato, muncul tidak dari ruang yang hampa. Ia mengada karena ada respon dari situasi yang melingkupinya. Di samping hal-hal tersebut di atas, kecakapan berbicara ini, menjadi sangat berkesinambungan dengan kultur di Indonesia karena masyarakat Indonesia cenderung untuk memiliki tradisi verbal yang lebih kuat dibandingkan dengan tradisi menulisnya. Alangkah baiknya kalau energi mereka diarahkan kepada penguasaan public speaking. Dalam metode public speaking, memungkinkan pembelajar untuk bisa mengekspos seluruh kemampuannya dalam hal berbicara. Akan tetapi lebih dari itu, pembelajar akan belajar bagaimana caranya memupuk rasa kepercayadiri dalam diri mereka. Mereka harus bisa menguasai rasa takut mereka dan rasa malu mereka di depan khalayak banyak. Adapun subjek pengabdian masyarakat ini adalah masyarakat yang terdiri remaja, bapak-bapak, ibu-ibu yang tergabung dalam PKBM Bakti Asih, Ciledug-Tangerang, Banten, Ciledug-Tangerang. Alasan pemilihan kepada lembaga ini dikarenakan PKBM Bakti Asih merupakan sebuah lembaga pendidikan paket A, B dan C yang tengah berkembang di Kota Tangerang, selain itu lembaga tersebut terbuka kajian ilmu pengetahuan secara universal. Diharapkan dengan adanya kegiatan pengabdian masyarakat ini, yang berisikan beberapa materi komunikasi dan pemahaman media yang bersandar pada metode publik speaking, sehingga menumbuhkan kesadaran bahwa dengan publik speaking dapat menambah kepercayaan diri pada seseorang individu.
\end{abstract}

Kata Kunci : komunikasi; public speaking; percaya diri; berita 


\section{Pendahuluan}

Komunikasi merupakan hal yang sangat esensial dalam kehidupan manusia, karena tanpa komunikasi, seorang manusia sangatlah mustahil untuk bisa menjalani kehidupannya dengan 'sukses' sebagai seorang makhluk sosial. Sukses atau tidaknya seseorang, ditengarai oleh bagaimana seseorang tersebut dapat mengkomunikasikan seluruh hal tentang dirinya, lingkungannya, ataupun bidang pekerjaannya. Terlebih, dalam era keterbukaan seperti sekarang, persaingan akan semakin sulit. Hal ini disebabkan karena unsur-unsur dari luar wilayah kenegaraan bisa masuk dan meramaikan persaingan. Apabila persaingan terjadi, tentunya, mereka yang mempunyai kompetensilah yang akan bisa memenangkannya. Oleh sebab itu, kompetensi dalam suatu bidang minimal harus dikuasai oleh seorang pembelajar apabila ia ingin bertahan dari 'terpaan angin' yang dinamakan persaingan. Untuk menguasai suatu kompetensi, dibutuhkan niat dan kerja keras serta usaha yang pantang menyerah, sehingga pada gilirannya akan mencapai target yang diinginkan. Dalam berproses ke arah itu, kita dituntut untuk sabar dan telaten dalam mengarunginya.

Dalam kehidupan nyata, komunikasi secara garis besar bisa terbagi menjadi dua arus besar yaitu komunikasi verbal dan komunikasi nonverbal. Komunikasi verbal secara luas bisa dimaknai sebagai komunikasi yang menggunakan bahasa lisan sebagai mediumnya. Sedangkan komunikasi nonverbal adalah komunikasi yang menjadikan sarana nonverbal sebagai media pelaksananya. Tipe komunikasi ini, bisa terlihat dan tergambar secara masif sekaligus gamblang di dalam buku, surat kabar, surat elektronik, sms, coretan dinding, dan media lainnya. Secara umum, di Indonesia, kuantitas pemakaian komunikasi verbal melebihi komunikasi nonverbal. Hal ini disebabkan karena masih kurangnya kesadaran masyarakat dalam memaknai sarana komunikasi nonverbal. Terlebih, hal ini ditengarai oleh minimnya kemampuan baca tulis masyarakat Indonesia. Tidak hanya itu saja, keadaan ini didukung oleh tradisi verbal yang masih berurat dan berakar dalam sebagian besar masyarakat Indonesia.

Hal-hal tersebut, tidak bisa dinilai sebagai sesuatu kekurangan atau terlebih kelemahan karena mungkin kebutuhan mereka untuk berperilaku demikian masih mendominasi keseluruhan hidup dan tata perilakunya. komunikasi verbal, dalam hal ini berhubungan dengan pidato, muncul tidak dari ruang yang hampa. Ia mengada karena ada respon dari situasi yang melingkupinya. Secara harfiah pembicaraan di depan publik adalah sebuah kemampuan untuk bertahan karena pembangunan dan kemajuan dalam kehidupan sosial atau lingkungan kerja sangatlah dipengaruhi oleh kemampuan kita dalam berbicara secara efektif. Di samping hal-hal tersebut di atas, kecakapan berbicara ini, menjadi sangat berkesinambungan dengan kultur di Indonesia karena masyarakat Indonesia cenderung untuk memiliki tradisi verbal yang lebih kuat dibandingkan dengan tradisi menulisnya. Alangkah baiknya kalau energi mereka diarahkan kepada penguasaan public speaking.

Dalam metode public speaking, memungkinkan pembelajar untuk bisa mengekspos seluruh kemampuannya dalam hal berbicara. Akan tetapi lebih dari itu, pembelajar akan belajar bagaimana caranya memupuk rasa kepercayadiri dalam diri mereka. Mereka harus bisa menguasai rasa takut mereka dan rasa malu mereka di depan khalayak banyak. Dengan beberapa landasan di atas maka kami berencana melakukan kegiatan pengabdian masyarakat dengan konsep "Pelatihan Public Speaking On Air Program Berita Dalam Meningkatkan Kepercayaan Diri Siswa PKBM Bakti Asih Ciledug Tangerang". Diharapkan dengan adanya kegiatan pengabdian masyarakat ini, yang berisikan beberapa materi komunikasi dan pemahaman media yang bersandar pada metode publik speaking, sehingga menumbuhkan kesadaran bahwa dengan publik speaking dapat menambah kepercayaan diri pada seseorang individu.

Adapun subjek pengabdian masyarakat ini adalah masyarakat yang terdiri remaja, bapakbapak, ibu-ibu yang tergabung dalam PKBM Bakti Asih, Jl. Raya Raden Fatah No. 7 Sudimara 
Barat, Ciledug-Tangerang, Banten, Ciledug-Tangerang. Alasan pemilihan kepada lembaga ini dikarenakan PKBM Bakti Asih merupakan sebuah lembaga pendidikan paket A, B dan C yang tengah berkembang di Kota Tangerang, selain itu lembaga tersebut terbuka kajian ilmu pengetahuan secara universal.

\section{Metode}

Metode yang digunakan untuk kegiatan pengabdian masyarakat ini adalah:

1. Survey/wawancara dilakukan kepada kelompok masyarakat yang menjadi target pelaksanaan program pengabdian masyarakat, guna mengetahui kebutuhan materi pelatihan yang diperlukan oleh peserta pelatihan.

2. Studi Pustaka

Mempelajari buku yang berkaitan dengan materi pelatihan:

a. Komunikasi adalah proses penyampaian pesan oleh seseorang kepada orang lain untuk memberitahu, mengubah sikap, pendapat, atau perilaku, baik secara lisan (langsung) ataupun tidak langsung (melalui media).

b. Public Speaking merupakan sebuah rumpun keluarga Ilmu Komunikasi (Retorika) yang mencakup berdiskusi, berdebat, pidato, memimpin rapat, moderator, MC, dan presenter serta kemampuan seseorang untuk dapat berbicara di depan publik, kelompok maupun perseorangan yang perlu menggunakan strategi dan teknik berbicara yang tepat.

c. Percaya Diri merupakan salah satu aspek kepribadian yang sangat penting dalam kehidupan manusia. Orang yang percaya diri yakin atas kemampuan mereka sendiri serta memiliki pengharapan yang realistis, bahkan ketika harapan mereka tidak terwujud, mereka tetap berpikiran positif dan dapat menerimanya. percaya diri adalah kondisi mental atau psikologis diri seseorang yang memberi keyakinan kuat pada dirinya untuk berbuat atau melakukan sesuatu tindakan. Orang yang tidak percaya diri memiliki konsep diri negatif, kurang percaya pada kemampuannya, karena itu sering menutup diri.

d. Teknologi ialah Metode ilmiah untuk mencapai tujuan praktis ilmu pengetahuan terapan Keseluruhan sarana untuk menyediakan barang- barang yang diperlukan bagi kelangsungan dan kenyamanan hidup manusia.

e. Berita dapat diartikan sebagai sebuah cerita ataupun keterangan yang memuat informasi mengenai berbagai kejadian ataupun peristiwa yang hangat.

\section{Hasil dan Pembahasan}

Kegiatan pengabdian masyarakat yang selanjutnya disingkat PKM merupakan salah satu dari komponen bagian penyelenggaraan tridarma yang meliputi kegiatan keilmuan yang dimiliki oleh Perguruan tinggi. Salah satu bentuk kegiatan yang dilakukan dapat disesuaikan dengan ranah keilmuan. Berdasarkan dari pemahaman tersebut, maka dilakukanlah kegiatan komunikasi yang disesuaikan kurikulum di lingkungan pendidikan. Institusi pendidikan bertujuan untuk meningkatkan pembangunan sumber daya manusia secara konstruktif, komprehensif dan prosesnya secara berkesinambungan. Sasaran dari kegiatan ini melibatkan Sekolah Pusat Kegiatan Belajar Masyarakat (PKBM) Bakti Asih yang beralamat di jalan Raya Raden Fatah No. 7 Sudimara Barat, Ciledug-Tangerang, Banten, Ciledug-Tangerang yang diketuai oleh H.U Nurul Iman,SH. 


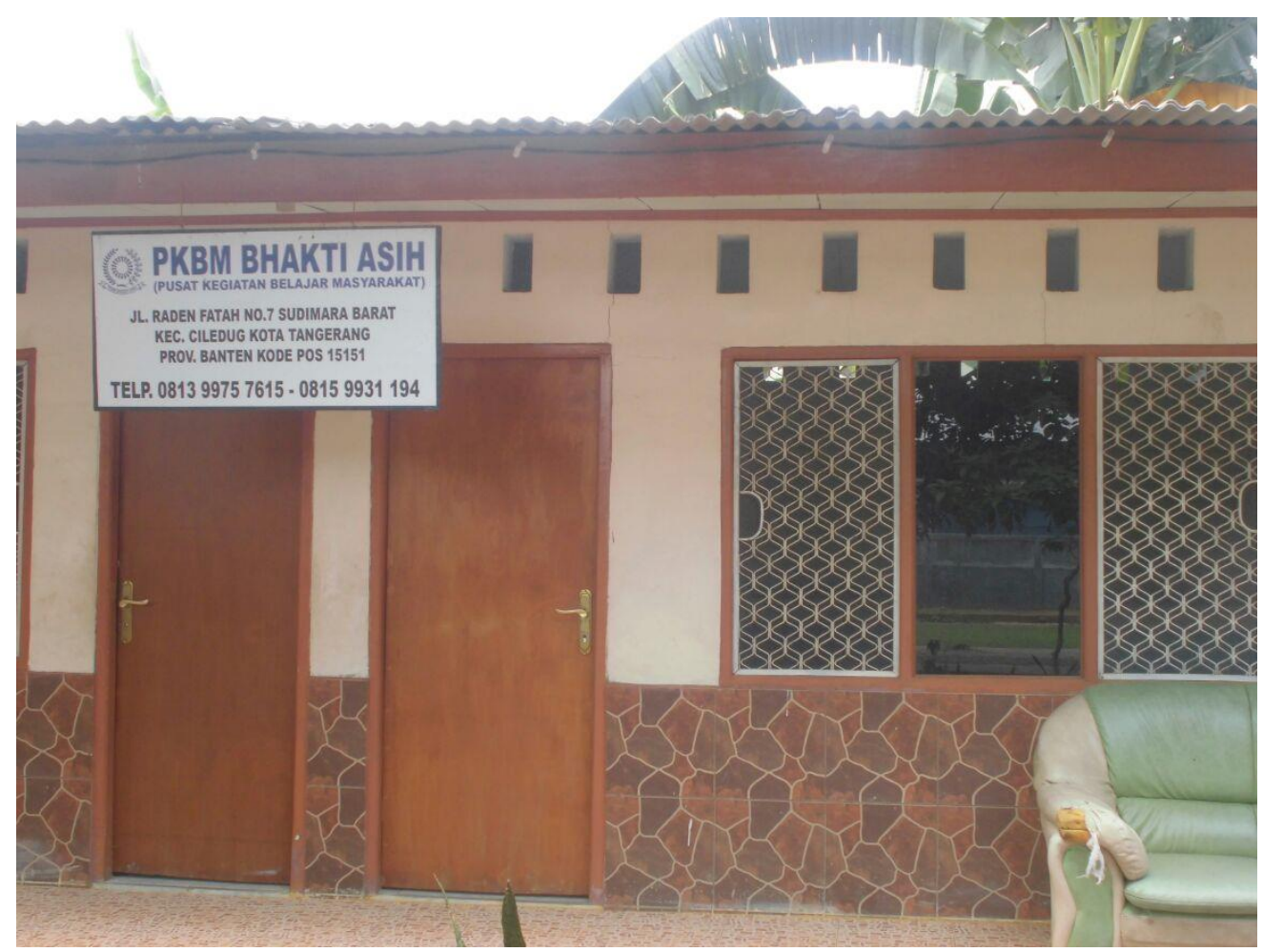

Gambar 1. Gedung PKBM Bakti Asih

Sekolah ini merupakan salah satu institusi pendidikan yang memiliki kurikulum berjenjang seperti paket A, B dan C. Sekolah ini terdiri dari siswa/siswi yang memiliki beragam latar belakang usia dan pekerjaan. Hanya saja, sasaran subjek peserta yang mengikuti kegiatan ini dikerucutkan bagi kelompok remaja yang berusia 15-25 tahun. Sekolah ini memiliki 108 peserta namun diklasifikasikan menjadi 20 orang. Adapun yang menjadikan alasan pengklasifikasian tersebut adalah usia-usia produktif yang dapat diarahkan kepada kemampuan soft skil dan vokasional.

Kegiatan ini dilaksanakan melalui 2 (dua) sesi pertemuan. Sesi 1 (satu) dipaparkan materi metode Public speaking dan Kegunaan public speaking pada media elektronik yang disampaikan oleh Jeanie Annissa. Sedangkan sesi 2 (dua) diberikan materi pembelajaran meliputi Pengenalan Produksi Berita dan praktek public speaking melalui Program Berita yang dipaparkan oleh Ricky Widyanandaputra. Dalam pelaksanaan sesi pertama, kegiatan dilakukan dengan penjabaran teoritis materi terkait metode public speaking yang meliputi metode spontanitas, manuskrip/teks/naskah, metode hapalan, dan terakhir metode extempore/catatan naskah dalam berpidato. Selanjutnya penjabaran diarahkan kepada bagaimana metode dalam public speaking tersebut kita terapkan dengan menggunakan media elektronik seperti radio, siaran podcast dan Televisi.

Dalam sesi kedua, kegiatan dilakukan dengan memanfaatkan studio TV yang berada di Laboratorium Media Komunikasi Universitas Budi Luhur. Masing-masing peserta diberi waktu untuk menyiapkan materi berita yang mau disampaikan dengan mengambil feature materi yang lebih soft /ringan seperti kegiatan keseharian yang terjadi di lingkungan masyarakat. Selanjutnya para peserta menuliskan naskah berita secara singkat sebagai penjelasan dari materi yang dipilih. Kemudian, para peserta melakukan shoot dengan memaparkan berita yang mereka pilih tersebut menggunakan kamera. Kegiatan ini memiliki tujuan agar para peserta memiliki pemahaman tentang pengertian dari Public Speaking dan metode-metode yang digunakan serta mempraktikan teori tersebut langsung menggunakan perangkat kamera dalam studio TV. Diharapkan kegiatan tersebut menambah pengetahuan dan keterampilan softskil/ bagi peserta tentang dunia komunikasi 
yang terkait public speaking dan metode komunikasinya serta pemahaman alur proses produksi berita dalam media komunikasi massa.

Pada sesi kedua tersebut juga dijelaskan proses-proses produksi program televisi yang melingkupi materi produksi yang menjelaskan material berita yang dapat diolah sehingga layak tayang, sarana produksi, biaya produksi, dan juga tahapan pelaksanaan produksi dari pra produksi yang berupa penemuan ide-ide, perencanaan, setting, tahap produksi hingga pasca produksi. Penjelasan dilakukan dalam bentuk pemaparan narasi sederhana.

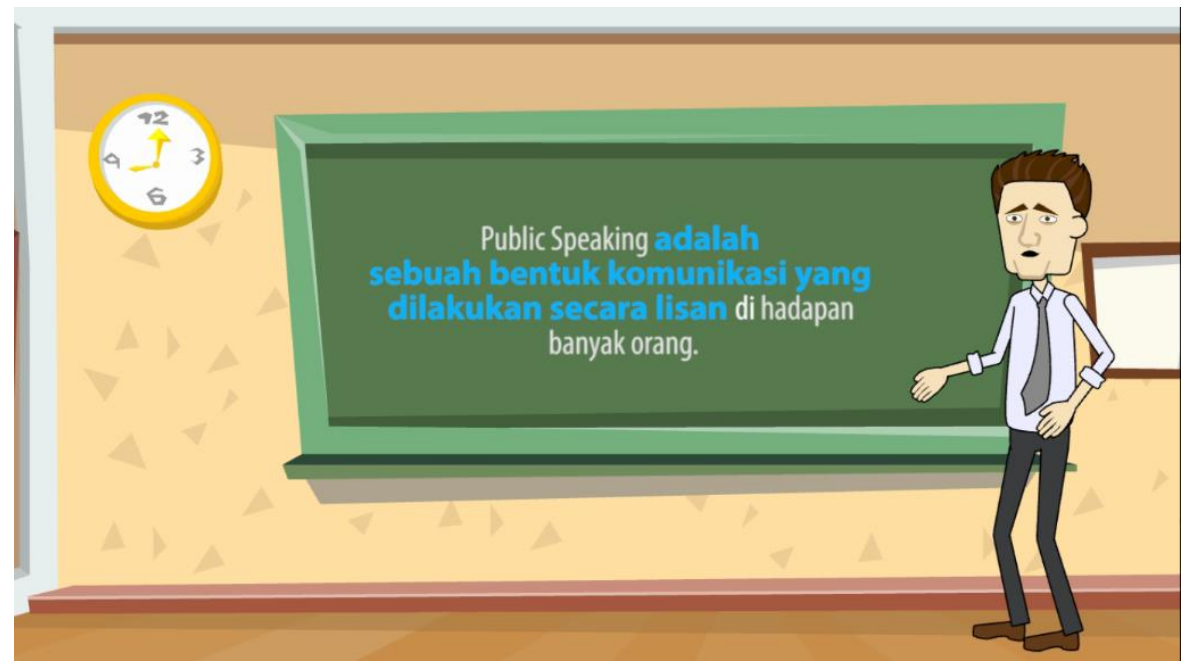

Gambar 2. Contoh Materi Terkait Dengan Public Speaking

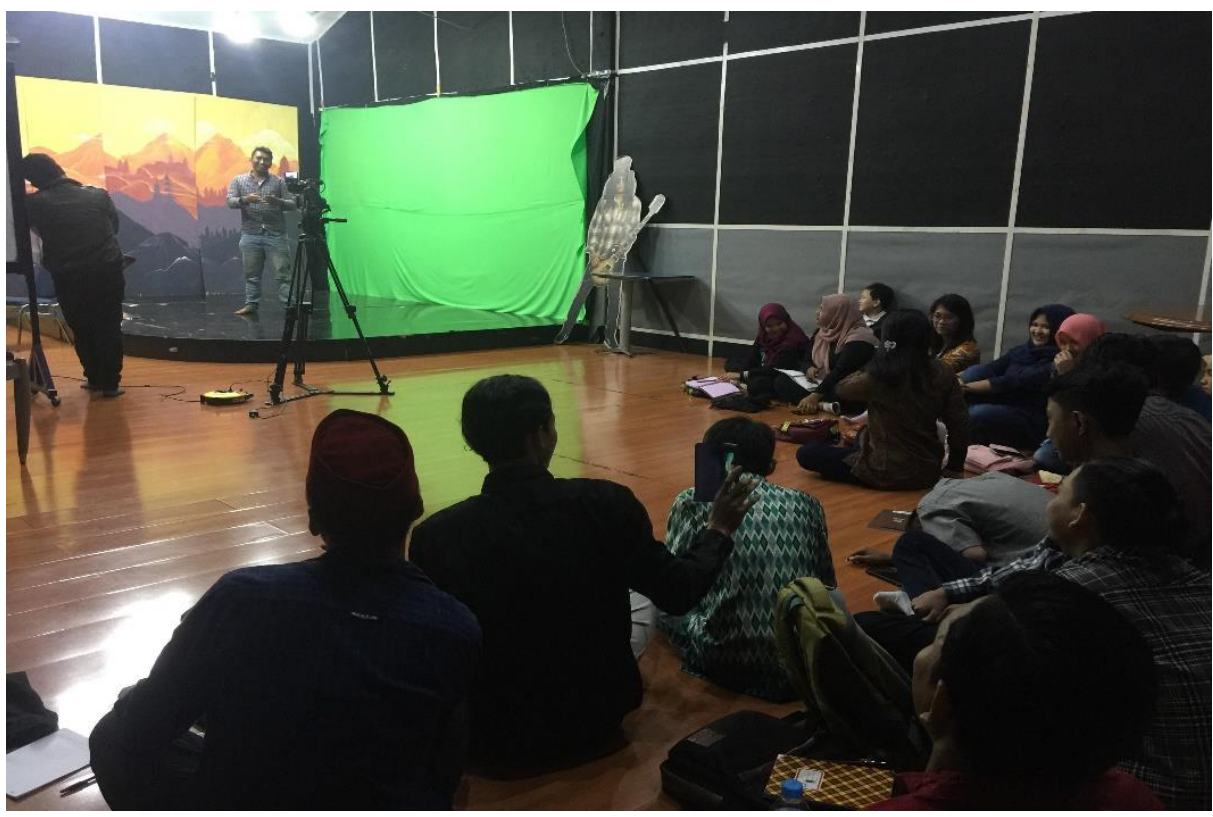

Gambar 3. Hasil Implemetasi Public Speaking Di Depan Kamera 


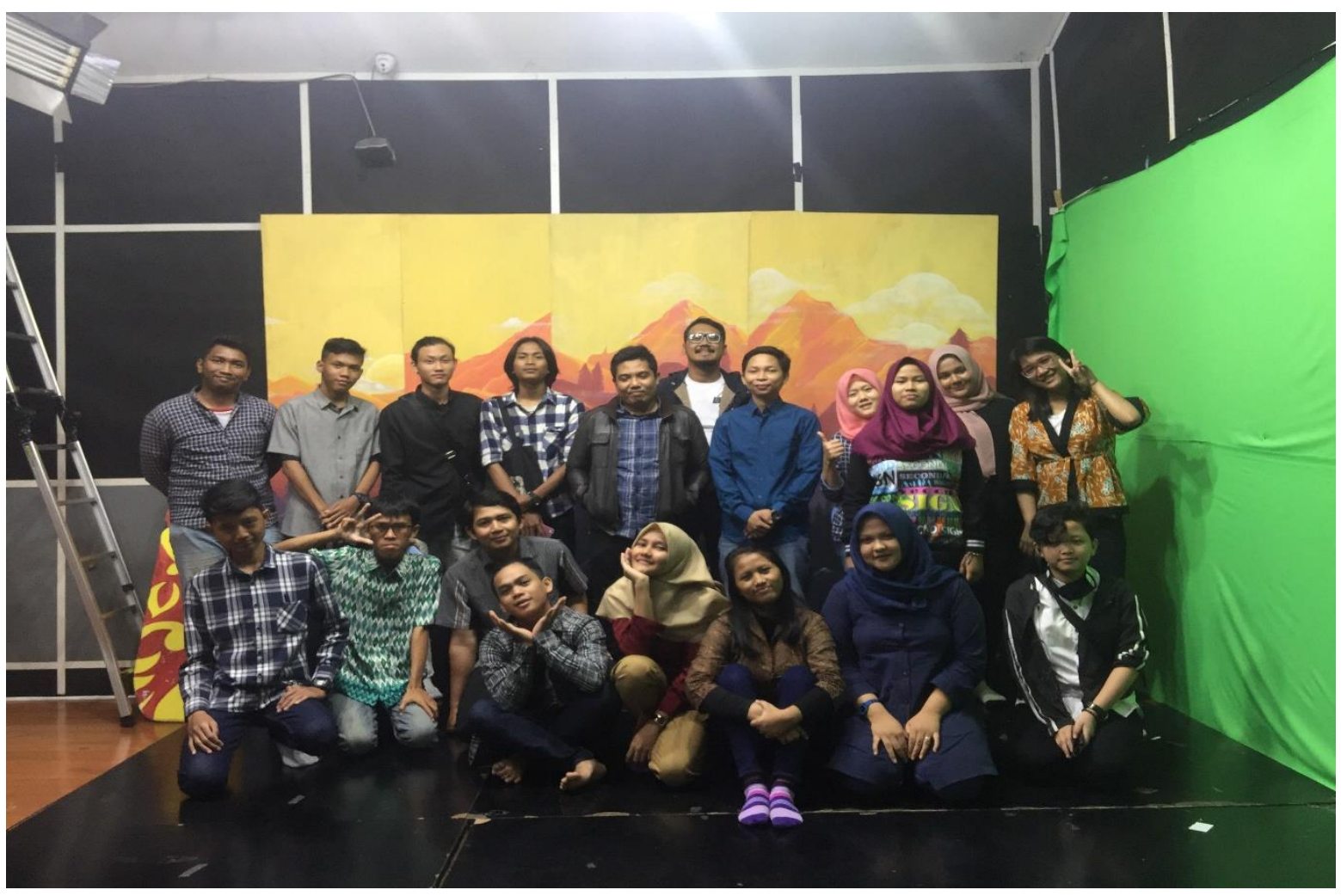

Gambar 4. Peserta Pelatihan Public Speaking Program Berita

\section{Kesimpulan}

Berdasarkan hasil pengamatan yang dilakukan dalam proses kegiatan pelaksanaan Pengabdian Kepada Masyarakat yang diikuti oleh 20 (dua puluh) siswa PKBM Bakti Asih Ciledug yang membahas tentang public speaking untuk program berita diperoleh kesimpulan bahwa, para peserta memiliki keberanian di dalam membuat naskah-naskah berita yang sederhana dari peristiwa-peristiwa yang terjadi di sekitar mereka yang selanjutnya dibacakan dengan berani dan penuh percaya diri di depan layar kamera menggunakan metode public speaking yang telah dipelajari. Dengan adanya Pelatihan Public Speaking Program Berita dapat menumbuhkan rasa Kepercayaan Diri Siswa PKBM Bakti Asih Ciledug Tangerang. Para peserta diharapkan memiliki soft skill pengetahuan tentang dunia public speaking dan gambaran singkat bahasan produksi berita. Mengingat besarnya manfaat kegiatan pengabdian pada masyarakat ini, maka selanjutnya perlu Mengadakan pelatihan lanjutan guna membuat peserta lebih mahir dalam bidang komunikasi dan adanya kesinambungan dalam materi ajar yang siswa dapat di PKBM Bakti Asih, dengan pelatihan yang diadakan.

\section{Daftar Pustaka}

Dinara Maya J dan Dewi Quraisyin, Buku Ajar Public Speaking, Universitas Trunojoyo, Madura, 2012.

Nieke Monika Kulsum, Modul Public Speaking, Universitas Nasional, Jakarta, 2017.

Buana Fanastar, Analisis Proses Produksi Siaran Berita Televisi Khabar Etam Di TVRI Kalimantan

Timur, e-Journal Ilmu Komunikasi, 2015 dapat dilihat dalam https://ejournal.ilkom.fisip- 
unmul.ac.id/site/wp-content/uploads/2015/11/jurnal\%20(11-30-15-06-48-12).pdf Tanggal akses 1 Desember 2020, 11.25 wib

http://www.seputarpengetahuan.com/2015/03/100-macam-pengertian-komunikasi-menurut-paraahli.html tanggal akses 1 Desember 2020, 13:45 WIB.

http://www.publicspeakingmagically.com/pengertian-public-speaking.html tanggal akses 1 Desember 2020, 13:08 WIB.

http://belajarpsikologi.com/pengertian-kepercayaan-diri/ tanggal Akses 1 Desember 2020, 13:35 WIB.

http://www.artikelteknologi.com/2015/05/definisi-teknologi-dan-pengertian-teknologi.html tanggal akses 18 Desember 2020, 10:45 WIB.

https://pengertiandefinisi.com/pengertian-berita-unsur-berita-dan-syarat-berita/ tanggal akses 18 Desember 2020, 13:45 WIB. 